\title{
Keterlibatan Perempuan dalam Aksi Terorisme di Indonesia
}

\author{
Sityi Maesarotul Qori'ah \\ Islam dan Kajian Gender Pascasarjana \\ UIN Sunan Kalijaga, Yogyakarta - Indonesia \\ email: sityicitiw@gmail.com
}

\begin{abstract}
The bomb blast in Surabaya which was an act of terrorism carried out by one family showed that women were actively involved in acts of terrorism. In the early days of the emergence of terrorism, women only acted as intermediaries, managing data through the internet network, fund collectors and driving "jihad" the husband who in fact was a terrorist. Based on this phenomenon, this paper wants to question what lies behind women's involvement in acts of terrorism? The literature review is used as a method to collect data related to women's involvement in acts of terrorism. This article will describe how women are involved in acts of terrorism. One of the successes of radicalism propaganda is actively involving women in acts of terrorism. Women as active actors in acts of terror will quickly be recognized if they show courage in jihad at the expense of their physical lives. His courage to become a 'martyr of the religion of God' was suspected to indicate the importance of a woman's piety.
\end{abstract}

Keywords: women; jihad; terrorism; radicalism

Abstrak: Ledakan bom di Surabaya yang merupakan aksi terorisme yang dilakukan oleh satu keluarga menunjukkan bahwa perempuan secara aktif terlibat dalam aksi terorisme. Pada masa awal kemunculan terorisme, perempuan hanya berperan sebagai perantara, pengelola data melalui jaringan internet, pengumpul dana dan pendorong "jihad" sang suami yang notabene seorang teroris. Berdasarkan fenomena inilah, tulisan ini mendeskripsikan keterlibatan perempuan dalam aksi terorisme. Kajian literatur digunakan sebagai metode untuk mengumpulkan data yang terkait dengan keterlibatan perempuan dalam aksi terorisme. Tulisan ini akan menguraikan keterlibatan perempuan dilibatkan dalam aksi terorisme. Salah satu keberhasilan propaganda radikalisme adalah melibatkan secara aktif perempuan dalam aksi terorisme. Perempuan sebagai pelaku aktif dalam aksi teror akan cepat diakui keberadaannya apabila mereka menunjukkan keberanian dalam berjihad dengan mengorbankan jiwa raga mereka. Keberaniannya menjadi 'martir agama Allah' ditengarai menunjukkan tingakat kesalehan seorang perempuan.

Kata Kunci: perempuan; jihad; terorisme; radikalisme 


\section{A. Pendahuluan}

Istilah terorisme mulai dikenal sejak tragedi 11 September 2001, tepatnya setelah penyerangan gedung World Trade Centre di Amerika. Dalam perkembangannya, terminologi terorisme kemudian sangat melekat dengan satu agama tertentu, yaitu Islam. Terorisme merupakan aksi kekerasan yang brutal yang dilakukan oleh kelompok tertentu, baik kelompok separatis, kelompok fundamental maupun kelompok radikal. Aksi terorisme dilakukan sebagai salah satu jalan 'jihad' dalam memperjuangkan Islam dengan pahala masuk surga dan pahala baik lainnya. Di Indonesia, tentu kita masih ingat dengan peristiwa ledakan bom di Bali tahun 2002, bom JW Marriot tahun 2003 dan bom di depan Kedutaan Australia, Kuningan dan Jakarta tahun 2004.1

Sejarah panjang terorisme di Indonesia yang menjadi kunci dan pelaku peledakan bom didominasi oleh laki-laki. Namun, aksi teror yang muncul barubaru ini memperlihatkan keterlibatan perempuan dalam menunaikan aksinya. Sebelumnya, keterlibatan perempuan dalam aksi teror hanya sebagai perantara (tandem) dan sebagai pelindung dari para pelaku teror. Nama-nama perempuan yang muncul dan kemudian dijatuhi hukuman pidana karena terlibat dalam proses aksi terorisme adalah Putri Munawaroh (istri Nurdin M. Top), Inggrid Wahyu Cahyaningsih (istri Sugeng Waluyo yang membantu pelaku teroris Bom Cimanggis), Munfiatun (istri kedua Nurdin M. Top) menyembunyikan pelaku aksi terorisme, Rasidah binti Subari (istri Husaini bin Ismail (buronan kasus pemboman di Singapura), Ruqayah binti Husen (istri Umar Patek), Deni Carmelita (istri Pepi Fernando pelaku bom buku dan bom Serpong), Rosmawati yang ikut terlibat dalam pendanaan untuk kelompok Santoso dan Arina Rahma istri ketiga Nurdin M. Top yang turut serta dalam menyembunyikan pelaku. ${ }^{2}$

Direktur Penindakan Badan Nasional Penanggulangan Teroris (BNPT) Brigjen Petrus Reinhard Golose pernah mensinyalir bahwa teroris mulai merekrut perempuan untuk ikut dalam aksi teror di Indonesia. Para perempuan yang direkrut itu kemudian ditempatkan di posisi strategis dalam perang yang dilakukan oleh organisasi teroris Islamic State in Iraq and Syiria (ISIS). ${ }^{3}$

\footnotetext{
1Mohd Adhe Bhakti, "Perempuan dan Terorisme," Pusat Kajian Radikalisme dan Deradikalisasi Radicalism Studies, 2016, https://www.radicalismstudies.org/96/2016/02/perempuan-danterorisme/.

2Bhakti.

${ }^{3}$ Aniek Nurhayati, “Dekonstruksi Feminitas dalam Gerakan Teroris di Dunia Islam," Jurnal Review Politik5, no. 1 (2015): 84-99, http://jurnalpolitik.uinsby.ac.id/index.php/jrp/article/view/61.
} 
Berikutnya para kelompok jihadis dari kalangan perempuan yang tergabung ke ISIS sebagian besar dipengaruhi oleh hubungan perkawinan. Menurut Lies Marcoes (Direktur Rumah Kita Bersama Foundation), seperti halnya dalam keluarga, para perempuan ekstrimis bertugas mengelola, menggalang dana, hingga melakukan kaderisasi. Ini menunjukkan gerakan teroris-ekstrimis kian berkembang di Indonesia. ${ }^{4}$

Pada tahun 2016, keterlibatan perempuan dalam aksi terorisme mulai terkuak dengan keterlibatan Dian Yulia Novi sebagai pelaku bom panci di Bekasi. Setelah itu muncul nama Ika Puspita Sari yang ikut terlibat dalam aksi bom bunuh diri di luar Jawa dan Umi Delima istri teroris Santoso di Poso. ${ }^{5}$ Aksi teror terbaru kembali menjadi sorotan publik setelah terjadi penyerangan dan penyanderaan yang dilakukan oleh narapidana teroris terhadap anggota kepolisian di Markas Komando Brigade Mobil (Mako Brimob) yang menewaskan lima penyidik polisi dan seorang narapidana teroris. Lalu tidak lama setelah penyerangan Mako Brimob, peledakan bom terjadi di Surabaya. Pelaku peledakan bom adalah satu keluarga yang terdiri dari ayah, ibu, dua anak laki-laki dan dua anak perempuan. ${ }^{6}$

Setelah peledakan bom di Surabaya, Markas Kepolisian Daerah Riau diserang oleh sekelompok teroris yang menewaskan seorang anggota kepolisian dan empat orang pelaku penyerangan. ${ }^{7}$ Belum selesai peristiwa peledakan bom di Surabaya dan penyerangan Markas Kepolisian Daerah Riau, muncul kembali dua perempuan muda (mahasiswa dan siswa) yang merencanakan untuk menyerang kembali Mako Brimob dengan cara akan melakukan penusukan terhadap anggota kepolisian Mako Brimob. Semua peristiwa peledakan bom tersebut merupakan wujud serangan yang berkaitan dengan Jamaah Ansharud Daulah (JAD) yang berafiliasi dengan Islamic State in Iraq and Syiria (ISIS). ${ }^{8}$

ISIS menjadi ancaman yang sangat mengerikan bagi keberlangsungan hidup beragama dan stabilitas keamanan negara. Tumbuh suburnya ISIS di

\footnotetext{
${ }^{4}$ Suprapto Suprapto, "Aksi Terorisme: Dari Gerakan Ideologis ke Gerakan Inkostitusional," Jurnal Sosiologi USK12, no. 2 (2018): 143-60, http://jurnal.unsyiah.ac.id/JSU/article/view/12598.

${ }^{5}$ Bhakti, "Perempuan dan Terorisme."

6M Faisal, "Bangkitnya Jihadis Perempuan," Tirto.ID, 2018, https://tirto.id/bangkitnya-jihadisperempuan-cKnp.

${ }^{7}$ Riyan Novitra, "Teror Polda Riau: 4 Teroris Ditembak Mati dan 1 Polisi Meninggal," NasionalTempo.co, 16 Mei 2018, https://nasional.tempo.co/read/1089450/teror-polda-riau-4-terorisditembak-mati-dan-1-polisi-meninggal.

8Faisal, "Bangkitnya Jihadis Perempuan."
} 
Indonesia merupakan bentuk suksesnya propaganda yang dilakukan oleh sang ideolog radikal. Proses radikalisasi pemikiran yang menafsirkan Islam sebagai agama yang paling benar diantara agama lainnya. ${ }^{9}$ Pun didalamnya bermuatan ideologi politik yaitu keinginan untuk penegakan sistem khilafah di Indonesia. Dari sekian banyak propaganda dan aksi teror, laki-laki mendominasi sebagi eksekutor atas tindakan tersebut. Kemaskulinan laki-laki digambarkan dengan keberanian mereka menghilangkan nyawa mereka sendiri dengan meledakan bom dan embel-embel pahala masuk surga.

Namun, baru-baru ini perempuan dan anak menjadi sasaran baru ISIS dalam memprogandakan ideologi mereka. Puncaknya, pada Minggu 13 Mei 2018 merupakan babak baru dalam aksi terorisme dengan target peledakan bom di rumah ibadah Surabaya, yaitu Gereja Santa Maria Tak Bercela, Gereja Kristen Indonesia dan GPPS Jemaat Sawahan dengan pelaku satu keluarga yaitu ayah (Dita Oepriarto), ibu (Puji Kuswati), dua anak laki-laki dan dua anak perempuan pelaku. Keluarga Dita Oepriarto ini diduga melakukan aksi terorime dengan meledakan bom setelah kembali dari Suriah.

Hal yang sama terjadi malam harinya, bom kembali meledak di Rumah Susun Sederhana Wonocolo, Kabupaten Sidoarjo dengan pelaku satu keluarga yaitu ayah (Anton Ferdiantono), ibu (Sari Puspitarini) dan putrinya yang masih berusia 17 tahun dan ketiga anak lainnya selamat. ${ }^{10}$ Tiga hari setelah kejadian bom Surabaya, terjadi lagi rencana penyerangan dengan melakukan penusukan terhadap polisi Mako Brimob oleh dua perempuan, yaitu Siska Nur Azizah dan Ditta Siska Millenia.

Keterlibatan perempuan dalam aksi terorisme sebagai pelaku utama menimbulkan kegelisahan tersendiri bagi seluruh elemen masyarakat, bahkan dinilai sebagai sejarah baru di Indonesia. Gema aksi terorisme ini bertambah besar karena pengaruh media massa, terutama televisi. Media massa merupakan sarana ampuh untuk penyebaran aksi teror.11 Komnas Perempuan menyatakan bahwa telah terjadi pemanfaatkan peran strategis perempuan sebagai ibu untuk mentransmisikan ideologi radikal dan mempersiapkan anak-

\footnotetext{
${ }^{9}$ Poltak Partogi Nainggolan, Ancaman ISIS di Indonesia (Jakarta: Yayasan Pustaka Obor Indonesia, 2017), 26.

10Tim Liputan Tempo, “Timang-timang Boom,” Majalah Tempo, 21-27 Mei 2018, 29.

${ }^{11}$ Hamzah Junaid, "Pergerakan Kelompok Terorisme dalam Perspektif Barat dan Islam," Sulesana: Jurnal Wawasan Keislaman 8, no. 2 (2013): 118-35, https://doi.org/10.24252/.V8I2.1285.
} 
anak menjadi martir.12 Perempuan dilibatkan dalam aksi brutal. Sementara selama ini perempuan senantiasa digambarkan sebagai makhluk yang mempunyai kelembutan dan cinta kasih seketika lenyap dengan keterlibatan mereka dalam aksi tersebut.

Namun, apakah sebenarnya ini adalah bentuk lain dari perlawanan perempuan pelaku teror terhadap isu-isu ketidaksetaraan yang senatiasa mengkonstruk perempuan sebagai makhluk yang lemah, tidak berdaya, tidak mempunyai keberanian menjadi berubah status sosialnya menjadi makhluk pemberani karena menjadi martir dengan iming-iming surga disebabkan telah memperjuangkan agamanya. Berdasarkan fenomena inilah, tulisan ini mengungkap hal yang melatarbelakangi keterlibatan perempuan dalam aksi terorisme.

\section{B. Propaganda Radikalisme Islam}

Dalam Kamus Besar Bahasa Indonesia (KBBI) radikalisme merupakan paham yang dianut oleh kelompok tertentu yang menginginkan perubahan, baik sosial maupun politik dengan menggunakan kekerasan. Irwan Masduqi menuturkan bahwa radikalisme (al-tatarruf) merupakan posisi yang berada pada posisi ektrem, jauh dari tengah-tengah, melampaui batas. ${ }^{13}$ Sedangkan, kaitannya dengan agama, radikalisme merupakan fanatisme keagamaan dari penganutnya. Sehingga, sangat mudah bagi mereka memberikan label kafir terhadap orang lain yang tidak sepaham dengan apa yang mereka yakini dengan menggunakan kekerasan. Radikalisme telah lama muncul ditandai dengan hadirnya jamaah jihadi. Jamaah jihadi adalah jamaah yang menganut teologi hakimiyah dan jihad. Bagi jamaah ini, keyakinan berada di tangan Allah dan hukum positif adalah bentuk hukum yang menganut sistem kekafiran. Sehingga harus diganti dengan hukum Allah. ${ }^{14}$

Radikalisme Islam didasarkan pada dua faktor. Pertama, sebagai sebuah ideologi dengan pendekatan yang memusatkan perhatian pada ideologis dan abai terhadap konteks sosial. Kedua, sebagai bentuk dari kelompok ekstrem.

\footnotetext{
${ }^{12}$ Dylan Aprialdo Rachman, "Tren Penggunaan Perempuan dalam Aksi Terorisme Harus Ditekan," nasional.kompas.com, 17 Mei 2018, https://nasionalkompas.com/read/2018/05/17/ 08145381/tren-penggunaan-perempuan-dalam-aksi-terorisme-harus-ditekan?page=all.

${ }^{13}$ Irwan Masduqi, Berislam secara Toleran: Teologi Kerukunan Umat Beragama (Bandung: Mizan, 2011), 117.

${ }^{14}$ Masduqi, 90.
} 
Radikalisme sangat erat kaitannya dengan doktrin dari kelompok tertentu sebagai kelompok ekstrim yang ingin menunjukkan bangkitnya Islam. ${ }^{15}$ Untuk memudahkan mengidentifikasi kelompok radikal kita dapat melihat dari karakteristik kelompok tersebut. Yusuf al-Qaradawi menjelaskan karakteristik kelompok radikal diantaranya adalah sebagai berikut: 1) Sering kali mengklaim kelompoknya sebagai kelompok dengan kebenaran tunggal dan menyesatkan kelompok lain yang tidak sependapat dengan mereka. 2) Radikalisme cenderung senang untuk mempersulit agama dengan menganggap bahwa ibadah yang hukumnya sunnah menjadi ibadah yang hukumnya wajib. 3) Dalam beragama, kelompok radikal cenderung over dalam memposisikan agama. 4) Akar radikalisme adalah sifatnya yang kasar dan emosional dalam berdakwah. 5) Kelompok radikal senantiasa su'u zan (berburuk sangka) terhadap mereka yang berbeda dengan kelompoknya. 6) Yang paling khas dari kelompok radikal adalah mudah mengkafirkan orang lain yang berbeda pendapat dengan kelompoknya. Kita dapat melihat pada masa munculnya kelompok ini, yaitu kelompok Khawarij. ${ }^{16}$

Tragedi 11 September 2011 di World Trade Center menjadi awal mula bahwa Islam merupakan agama yang sangat melekat dengan kekerasan. Kekerasan ini yang senantiasa digaungkan oleh kelompok radikal. Stereotipe radikalisme kemudian sangat melekat dengan terorisme. Sejak tahun 2015, tragedi peledakan bom yang dilakukan oleh teroris merupakan implikasi dari suksesnya propaganda radikalisme di Indonesia. Pada waktu itu, aksi teror yang terjadi sangat melekat dengan Jama'ah Ansharud Daulah (JAD) yang berafiliasi dengan ISIS.

ISIS merupakan gerakan yang menginginkan kekhilafahan Islam lintas negara di Timur Tengah. ISIS mengatasnamakan dirinya Islamic State, sehingga gerakannya tidak hanya di Irak dan Suriah. ${ }^{17}$ Namun, telah menyebar ke berbagai negara termasuk Indonesia. Penyebaran paham radikal ISIS berlangsung melalui pimpinannya yang telah menjadi narapidana dan kemudian membawa banyak pengikut lainnya. Salah satu pendukung ISIS di Indonesia adalah JAD. JAD merupakan salah satu jaringan ISIS di Indonesia. Pimpinan JAD adalah

\footnotetext{
${ }^{15}$ Mohamad Ulin Nuha, "Genealogi dan Ideologi Gerakan Radikal Islam Kontemporer di Indonesia," Intelegensia: Jurnal Manajemen Pendidikan Islam 3, no. 1 (2014).

16Masduqi, Berislam secara Toleran, 117-9.

${ }^{17}$ Nainggolan, Ancaman ISIS di Indonesia, 25.
} 
Aman (Oman) Abdurrahman. Namun, karena Aman saat ini menjadi narapidana Nusakambangan, maka pimpinan sementara adalah Marwan (Abi Musa). ${ }^{18}$

JAD tidak berdiri sendiri, ia terdiri dari beberapa faksi yaitu Jama'ah Ansharul Tuhid (JAT), Jama'ah Ansharul Khilafah (JAK), Mujahidin Indonesia Timur (MIT), dan Mujahidin Indonesia Barat (MIB), serta kelompok AlMuhajirun yang merupakan sempalan dari kelompok Hizbut Tahrir (HT). JAD berusaha membentuk jaringan global dengan mengadvokasi kelompokkelompok yang mendukung penegakan syariat Islam yaitu dengan cara

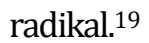

ISIS telah banyak memikat hati masyarakat yang tidak benar-benar paham akan agama dan tidak mempunyai latar belakang agama yang kuat. Pun banyak yang belajar tentang jihad dan ISIS dari media sosial, baik kelas bawah maupun kelas menengah. Banyaknya masyarakat yang bergabung dengan ISIS, menurut Noor Huda Ismail seorang pengamat terorisme, merupakan akibat dari keresahan spritual personal yang tidak terakomodasi. ${ }^{20}$ Keresahan-keresahan inilah yang kemudian dimanfaatkan oleh ISIS untuk terus mempropagandakan ideologinya kepada mereka yang masih 'labil' akan kondisi spiritualnya.

Target ISIS untuk menjadi martir tidak lagi didominasi oleh laki-laki. ISIS telah berhasil menarik minat para perempuan untuk bergabung dengan gerakannya. Sidney Jones seorang pakar terorisme menjelaskan bahwa 40 perempuan Indonesia dan 100 anak-anak dibawah umur 15 tahun telah memutuskan untuk bergabung dengan ISIS dan belajar langsung di Suriah. Institute for Policy Analysis of Conflict (IPAC) dalam hasil penelitiannya menjelaskan bagaimana perempuan akhirnya tertarik untuk bergabung dengan ISIS melalui telepon seluler. Telepon seluler digunakan sebagai alat untuk "menyatukan aliansi, memperkuat hierarki sosial, memenuhi kebutuhan biologis tahanan atau membawa perempuan ke Timur Tengah". Dalam konteks Indonesia, ketertarikan perempuan bergabung dengan ISIS ataupun dengan gerakan radikal

\footnotetext{
${ }^{18}$ Nainggolan.

${ }^{19}$ Najamuddin Khairur Rijal, "Eksistensi dan Perkembangan ISIS: Dari Irak Hingga Indonesia," Jurnal Ilmiah Hubungan Internasional 13, no. 1 (2017): 45-60, https://doiorg/10.26593/jihiv13i1.2670.45-60.

${ }^{20}$ Joko Panji Sasongko, "ISIS dan Fenomena Radikalisme Keagamaan Kelas Menengah," cnnindonesia.com, 1 Februari 2017, https://www.cnnindonesia.com/nasional/20170201135943-20190578/isis-dan-fenomena-radikalisme-keagamaan-kelas-menengah.
} 
lainnya adalah budaya patriarkal yang senantiasa mengkonstruks perempuan sebagai manusia yang lemah dan tidak berani seperti laki-laki untuk melakukan tindakan kekerasan melalui aksi teror. Keinginan dan kesadaran perempuan akan penegakan negara Islam (khilafah) yang didasarkan pada hukum-hukum agama Islam. ${ }^{21}$

Seperti yang terjadi di Surabaya dengan adanya pelibatan perempuan dan anak dalam aksi teror. Harits Abu Ulya, seorang pengamat terorisme dari The Community Ideologica Islamic Analyst menjelaskan bahwa pelibatan perempuan dan anak merupakan sebuah pesan baru dari jaringan JAD. Tujuannya adalah untuk mengaburkan jejak teroris laki-laki. Keberadaan pelaku teror perempuan dan anak menjadi solusi agar lepas dari pantauan polisi. ${ }^{22}$ Pun untuk menunjukkan bahwa perempuan dan anak pun berani menjadi martir peledakan bom. Namun, sebenarnya perempuan dan anak telah kehilangan agensi mereka karena tetap saja menjadi korban dominasi laki-laki didalam propaganda radikal.

\section{Terorisme: 'Jihad' sebagai Jalan Menuju Surga}

Secara etimologis, jihad berarti aktivitas yang dilakukan oleh manusia secara sadar yang melibatkan dua pihak dimana keduanya berusaha untuk saling mengalahkan. Sementara al-Qastalani mendefinisikan jihad sebagai "peperangan dengan orang kafir dengan tujuan untuk menegakkan Islam dan kalimat tauhid".23 Dalam perkembangannya, jihad memang diyakini sebagai 'perang' (qitāl). Kaitannya dengan teorisme, arti jihad berkembang menjadi sesuatu yang mengharuskan untuk memerangi musuh Islam dan orang-orang kafir.

Gagasan besar terorisme adalah tindakan kekerasan merupakan cara yang dinilai tepat untuk menyelesaikan berbagai permasalahan di suatu negara, baik itu menyangkut politik (political violence) ataupun agama. Terorisme merupakan suatu upaya yang terorganisir yang dikendalikan oleh sistem yang dikonstruks sedemikian rapi untuk menciptakan suasana mencekam dan menakutkan. Suasana tersebut adalah yang diinginkan oleh pelaku teror agar

\footnotetext{
${ }^{21}$ Lies Marcoes, "Why do Indonesian women join radical groups?," Indonesia at Melbourne University of Melbourne, 26 November 2015, https://indonesiaatmelbourne.unimelb.edu.au/why-doindonesian-women-join-radical-groups/.

${ }^{22}$ Felix Nathaniel, “Analisis Serangan Bom di Surabaya: Taktik dan Pesan Baru Teroris,” Tirto.ID, 16 Mei 2018, https://tirto.id/analisis-serangan-bom-di-surabaya-taktik-dan-pesan-baru-teroris-cKuj.

${ }^{23}$ Masduqi, Berislam secara Toleran: Teologi Kerukunan Umat Beragama.
} 
masyarakat merasa takut, stabilitas keamanan suatu negara terancam, struktur kekuasaan hancur dengan upaya-upaya sabotase baik itu peledakan bom atau lainnya. ${ }^{24}$ Dari kesemua aksi teror, pada dasarnya merupakan aksi tak bermoral, karena merugikan banyak orang dan mengancam ketentraman kehidupan bermasyarakat.

Namun, kebanyakan aksi terorisme adalah mengatasnamakan 'jihad' atas nama agama Islam. Jihad dalam hal ini dimaknai sebagai aksi yang bermuatan kekerasan. Padahal didalam Islam sendiri sama sekali tidak dianjurkan untuk melakukan kekerasan terhadap sesama manusia. Tentu kita semua akan sepakat bahwa jihad yang senantiasa digaungkan oleh pelaku teror ataupun sekelompok yang senatiasa menebar ideologi radikal adalah aksi tak bermoral. Sama sekali bukan jihad dalam arti yang sesungguhnya.

Di dalam al-Qur'an sama sekali tidak dianjurkan melakukan aksi teror seperti yang selama ini diyakini oleh pelaku teror. Di dalam Surat al-Anfal ayat 60 ditemukan makna yang sama dengan kata teroris yaitu 'al-irhab' yang berarti menggetarkan atau membuat takut atau diartikan sebagai teroris. Terorisme diterjemahkan dalam bahasa Arab yaitu 'irhabiyah'. Irhabiyah yang dimaksud di dalam al-Qur'an mengandung muatan dan makna terhadap perilaku seseorang dalam kebaikan, sedangkan terorisme merupakan sebuah tindakan yang bertujuan untuk membuat orang merasa takut, tidak aman dan tentunya menghilangkan nyawa orang-orang yang tidak berdosa. ${ }^{25}$ Barangkali inilah hujjah (pembenaran) atas apa yang selama ini dilakukan oleh pelaku teror. Padahal hujjah tersebut sama sekali tidak dibenarkan dalam al-Qur'an ataupun oleh hukum dan norma sosial.

Konsep jihad yang dipahami dalam aksi teror merupakan bentuk kesalahan berpikir. Bagaimana bisa jihad dengan cara menghilangkan nyawa orang-orang yang tidak berdosa dan melibatkan anak-anak dalam aksi tersebut. Jihad sering dimaknai dengan perang dengan cara kekerasan. Artinya, dengan membuat orang lain takut. Jihad sering diyakini sebagai upaya dalam memperjuangkan agama dengan cara perang melawan orang kafir. ${ }^{26}$ Aksi teror diyakini pula sebagai salah satu cara perang melawan musuh Islam dan orang-

\footnotetext{
24Tabrani Sabirin, ed., Menggugat Terorisme (Jakarta: Karsa Rezeki, 2002), 34.

${ }^{25}$ Muhammad Nur Islami, Terorisme Sebuah Upaya Perlawanan (Yogyakarta: Pustaka Pelajar, 2017), 311-3.

26Islami, 313.
} 
orang kafir yang tidak seideologi. Klaim agama dalam aksi teror merupakan hal yang paling mudah untuk diidentifikasi. Namun, motif jihad sebenarnya merupakan keinginan untuk menegakkan negara Islam di suatu negara. Tujuan penegakan negara Islam tentunya syarat dengan muatan politik dan agama kemudian ditunggangi oleh para teroris dalam aksinya.

Lies Marcoes menjelaskan bahwa konsep jihad yang diyakini oleh perempuan yang terlibat di dalam aksi terorisme merupakan bentuk kesadaran dan keinginan mereka agar dilibatkan dalam aksi teror dan upaya untuk melawan kezaliman dan musuh Allah. Radikalisme menanamkan konsep jihād kabïr, yaitu dengan turun langsung ke medan perang atau dengan kata lain menjadi pelaku aktif dalam aksi teror dan itu merupakan tugas laki-laki. Sementara perempuan menjadi pendorong dan penguat bagi para laki-lakinya (suami). Peran lainnya dari seorang perempuan adalah menjadi seorang yang menyiapkan jundi (anak lelaki) yang akan menjadi jundullāh (tentara Allah). ${ }^{27}$ Secara keseluruhan, peran perempuan dalam aksi terorisme yang dipropagandakan oleh radikalisme bukanlah menjadi pelaku sentral. Inilah yang kemudian menjadi kunci yang paling penting untuk mengidentifikasi keterlibatan perempuan dalam aksi terorisme.

\section{Perempuan dalam Jeratan Teror}

Munculnya pelaku baru dalam aksi teror yang melibatkan perempuan dan anak menegaskan bahwa konsep jihad tidak hanya diwajibkan untuk muslim laki-laki, namun berlaku pula untuk muslim perempuan. Propaganda atas nama agama menjadi salah satu hal yang mudah untuk menarik minat perempuan agar mau menjadi martir dalam aksi teror. Peran perempuan dalam aksi teror tidak lagi sebagai perantara ataupun pelindung dari para suaminya yang juga teroris. Namun, bagaimana perempuan dipaksa dan dicuci otaknya untuk menjadi pelaku aktif dalam aksi teror.

Sebelum tragedi bom Surabaya dan Sidoarjo, keterlibatan perempuan dalam aksi teror telah terjadi sejak tahun 2014. Seperti yang disampaikan oleh Direktur Penindakan Badan Nasional Penanggulangan Terorisme (BNPT) bahwa teroris mulai merekrut perempuan agar terlibat dalam aksi teror. Akhir tahun 2016, ketelibatan perempuan dalam aksi teror ditunjukkan oleh Dian

${ }^{27}$ Lies Marcoes, "Bagaimana para perempuan menjadi pelaku teror dan membawa anak?," $B B C$ News Indonesia, 14 Mei 2018, https://www.bbc.com/indonesia/indonesia-44106870. 
Yulia Novi dan Ika Puspitasari. Dian telah mengikuti doktrin ekstrimisme secara daring di bawah instruksi JAD yang berafiliasi dengan ISIS. Dian adalah seorang buruh migran di Taiwan, ia mulai belajar tentang 'jihad' karena ketertarikannya terhadap propaganda negara Islam yang digaungkan oleh ISIS. Ia berkenalan dengan simpatisan ISIS, yaitu Nur Solihin. Kemudian mereka pun menikah yang didorong karena semangat berjihad dalam diri keduanya. ${ }^{28}$

Dian Yulia Novi menjadi perempuan pertama yang melakukan aksi teror dengan meledakkan bom di Bekasi. Namun, aksinya tersebut berhasil digagalkan oleh Densus 88. Serupa dengan Dian, Ika Puspitasari mantan buruh migran di Hongkong berencana untuk meledakkan diri di Bali bersamaan dengan perayaan tahun baru 2016. Namun, aksinya kembali digagalkan dan Ika ditangkap oleh Densus 88. Berselang dua tahun kemudian, aksi penyerangan yang dilakukan oleh perempuan kembali dilakukan oleh dua perempuan muda, Siska Nur Azizah dan Dita Siska Millenia yang berencana melakukan penusukan terhadap anggota kepolisian di Mako Brimob.

Berdasarkan hasil wawancara terhadap dua pelaku aksi penyerangan Mako Brimob yang dilakukan oleh Tempo, Siska dan Dita menjelaskan bahwa mereka berdua simpati terhadap para terpidana teroris dalam memerangi thaghut. Thaghut yang dimaksud adalah pemerintah Indonesia, termasuk polisi dan Dewan Perwakilan Rakyat (DPR). Siska merupakan seorang mahasiswa di salah satu perguruan tinggi di Bandung, Universitas Pendidikan Indonesia (UPI). Siska bergabung dengan ISIS sejak tahun 2017, ia dibaiat oleh pemimpin ISIS Abu Bakar al-Baghdadi melalui saluran Daulah di Telegram. Siska mempelajari ISIS melalui internet dengan mendengarkan ceramah-ceramah pimpinan JAD Aman Abdurrahman. Siska sangat setuju dengan propaganda ISIS, menurutnya ISIS senantiasa memperjuangkan berdirinya Daulah Islam yang sesuai dengan perintah Rasul. Sementara, demokrasi yang diterapkan di Indonesia menurutnya merupakan lingkaran setan. ${ }^{29}$

Serupa dengan Siska, Dita pun tertarik untuk bergabung dengan ISIS karena ia pun berkeinginan agar ISIS eksis di seluruh dunia. Ia tidak setuju dengan sistem demokrasi yang ada di Indonesia, menurutnya haram karena

\footnotetext{
${ }^{28}$ Faisal, "Bangkitnya Jihadis Perempuan." 2018,48 .

${ }^{29}$ Tim Liputan Tempo, "Investigasi: Paham Radikal di Kampus Kita," Majalah Tempo, 27 Mei
} 
demokrasi merupakan sistem buatan manusia. Menurutnya perempuan pun boleh untuk berperang dan memerangi mereka yang tidak menjalankan hukum Islam, itulah yang diajarkan oleh ISIS. Sama dengan Siska, Dita belajar tentang ISIS secara otodidak dengan memanfaatkan grup WhatsApp dan channel Telegram sejak tahun 2017. Dari hasil wawancara keduanya, menunjukkan kepolosan dan ketidakpahaman mereka akan pemahaman agama yang sebenarnya. Terlihat bagaimana otak keduanya berhasil dicuci dengan pahampaham radikal yang terus dipropagandakan oleh ISIS.30

Ketiga aksi teror yang melibatkan perempuan di atas berhasil digagalkan dan pelakunya berhasil ditangkap. Dalam hal ini bisa dilihat bahwa keterlibatan perempuan dalam aksi teror masih gagal, karena mereka bergerak sendirian tanpa rekannya (laki-laki yang menjadi suaminya). Ini menunjukkan pula bahwa ketidakmampuan perempuan dalam keterlibatannya untuk melakukan tindak kekerasan dalam aksi teror. Keterlibatan perempuan dalam aksi teror benarbenar berhasil dalam tragedi peledakan bom di Surabaya dan Sidoarjo yang melibatkan satu keluarga. Sidney Jones menegaskan kembali bahwa ISIS telah berhasil mengubah konsep jihad personal menjadi jihad keluarga yang melibatkan istri dan anak-anak. Menurutnya, perempuan berperan sebagai singa betina, sedangkan anak-anak sebagai anak singa. Setiap orang yang telah bergabung dengan ISIS diberikan misi masing-masing. ${ }^{31}$

Dalam risetnya, IPAC membagi peran perempuan dalam aksi terorisme di Indonesia. yaitu sebagai pengelola forum percakapan daring, mengumpulkan dana, merekrut anggota dan menjadi tandem pasangan pelaku peledakan bom. Direktur Rumah Kita Bersama Foundation, Lies Marcoes menjelaskan bahwa ada dua faktor yang melatarbelakangi ketertarikan perempuan dalam aksi terorisme di Indonesia. Pertama, bahwa perempuan setuju dan percaya dengan gagasan khilafah. Khilafah sebagai suatu sistem yang sesuai dengan syariat Islam dan sebagai jawaban atas berbagai kesenjangan sosial-ekonomi. Bergabungnya perempuan dengan kelompok teroris merupakan bentuk kesadaran mereka akan isu-isu ketidakadilan, ketidaksetaraan dan kekecewaan atas kesenjangan ekonomi. Mereka percaya bahwa semua kegelisahan mereka dapat diselesaikan dengan jalan kekerasan yaitu dengan aksi terorisme. Kedua, budaya patriarkal

${ }^{30}$ Tim Liputan Tempo, 49.

${ }^{31}$ Nathaniel, "Analisis Serangan Bom di Surabaya: Taktik dan Pesan Baru Teroris.” 
yang mengakar dalam tradisi muslim konservatif yang senantiasa menempatkan perempuan pada posisi kedua setelah laki-laki. Menurut mereka, kelompok radikal dapat menampung apa yang mereka inginkan dan melibatkan perempuan dalam aksi teror. Inilah yang mereka yakini sebagai bentuk 'kesetaraan' yang mereka dapatkan agar posisi mereka sama dengan laki-laki yang berani berjihad di jalan Allah. ${ }^{32}$

\section{E. Kesimpulan}

Konsep jihad yang senantiasa dianut oleh para pelaku teror merupakan pemahaman keagamaan yang salah karena telah merugikan banyak orang dan merusak tatanan sosial suatu negara. Para pelaku teror meyakini bahwa menjadi martir dalam jihad atas nama agama Allah (Islam) ganjarannya adalah surga. Philip Chard menegaskan bahwa teroris sama sekali tidak mempunyai penyesalan telah menghilangkan nyawa orang lain. Menghilangkan nyawa orang lain dalam aksinya merupakan tujuan yang sebenar-benarnya dan itulah yang menjadi kebahagiaan bagi mereka. Pertumpahan darah merupakan sumber kebahagiaan dan jalan mereka menuju surga. ${ }^{33}$

Paham yang seperti inilah yang kemudian sangat membahayakan. Apalagi di era digital seperti sekarang sangat mudah untuk siapa saja mengakses segala bentuk pembelajaran yang bersumber dari paham radikal dan ajakan-ajakan untuk berjihad melalui aksi teror dengan embel-embel ganjaran surga. Pelibatan perempuan dalam aksi terorisme di Indonesia menjadi hal baru. Bagaimana perempuan dilibatkan dalam aksi teror yang syarat dengan muatan politik dan tindak kekerasan yang senantiasa menggaungkan jihad atas nama agama.

Pelibatan perempuan merupakan salah satu bentuk pengakuan kelompok radikal akan isu ketidaksetaraan dan ketidakadilan yang senantiasa memposisikan perempuan sebagai makhluk yang lemah. Bagaimana perempuan dijadikan sebagai alat perbandingan untuk laki-laki atas keberanian mereka menjadi pelaku aktif dalam aksi terorisme. Bagaimana perempuan dikendalikan oleh paham-paham radikal. Sehingga, memunculkan cuitan dari para pelopor jihadis. Jika perempuan dan anak-anak saja berani menjadi martir, maka lakilaki harus lebih berani dari pada perempuan dan anak-anak mereka.[s]

\footnotetext{
${ }^{32}$ Researchers Team, "Mothers to Bombers: The Evolution of Indonesian Women Extremists," 2017, https://www.jstor.org/stable/resrep07796.

${ }^{33}$ Harun Yahya, Teroris Hanya Taklukoleh Cinta (Jakarta: Iqra Insan Press, 2004).
} 


\section{Daftar Pustaka}

Bhakti, Mohd Adhe. "Perempuan dan Terorisme." Pusat Kajian Radikalisme dan Deradikalisasi - Radicalism Studies, 2016. https://www.radicalismstudies. org/96/2016/02/perempuan-dan-terorisme/.

Faisal, M. "Bangkitnya Jihadis Perempuan." Tirto.ID, 2018. https://tirto.id/ bangkitnya-jihadis-perempuan-cKnp.

Islami, Muhammad Nur. Terorisme Sebuah Upaya Perlawanan. Yogyakarta: Pustaka Pelajar, 2017.

Junaid, Hamzah. "Pergerakan Kelompok Terorisme dalam Perspektif Barat dan Islam." Sulesana: Jurnal Wawasan Keislaman 8, no. 2 (2013): 118-35. https://doi.org/10.24252/.V8I2.1285.

Marcoes, Lies. "Bagaimana para perempuan menjadi pelaku teror dan membawa anak?" BBC News Indonesia, 14 Mei 2018. https://www.bbc.com/ indonesia/indonesia-44106870.

-_- "Why do Indonesian women join radical groups?" Indonesia at Melbourne University of Melbourne. 26 November 2015. https://indonesiaatmelbourne. unimelb.edu.au/why-do-indonesian-women-join-radical-groups/.

Masduqi, Irwan. Berislam secara Toleran: Teologi Kerukunan Umat Beragama. Bandung: Mizan, 2011.

Nainggolan, Poltak Partogi. Ancaman ISIS di Indonesia. Jakarta: Yayasan Pustaka Obor Indonesia, 2017.

Nathaniel, Felix. "Analisis Serangan Bom di Surabaya: Taktik dan Pesan Baru Teroris." Tirto.ID, 16 Mei 2018. https://tirto.id/analisis-serangan-bom-disurabaya-taktik-dan-pesan-baru-teroris-cKuj.

Novitra, Riyan. "Teror Polda Riau: 4 Teroris Ditembak Mati dan 1 Polisi Meninggal." Nasional.Tempo.co. 16 Mei 2018. https://nasional.tempo.co/read/ 1089450/teror-polda-riau-4-teroris-ditembak-mati-dan-1-polisimeninggal.

Nuha, Mohamad Ulin. "Genealogi dan Ideologi Gerakan Radikal Islam Kontemporer di Indonesia." Intelegensia: Jurnal Manajemen Pendidikan Islam 3, no. 1 (2014). 
Nurhayati, Aniek. "Dekonstruksi Feminitas dalam Gerakan Teroris di Dunia Islam." Jurnal Review Politik 5, no. 1 (2015): 84-99. http://jurnalpolitik.uinsby. ac.id/index.php/jrp/article/view/61.

Rachman, Dylan Aprialdo. "Tren Penggunaan Perempuan dalam Aksi Terorisme Harus Ditekan." nasional.kompas.com, 17 Mei 2018. https://nasional. kompas.com/read/2018/05/17/08145381/tren-penggunaanperempuan-dalam-aksi-terorisme-harus-ditekan?page=all.

Researchers Team. "Mothers to Bombers: The Evolution of Indonesian Women Extremists," 2017. https://www.jstor.org/stable/resrep07796.

Rijal, Najamuddin Khairur. "Eksistensi dan Perkembangan ISIS: Dari Irak Hingga Indonesia." Jurnal Ilmiah Hubungan Internasional 13, no. 1 (2017): 45-60. https://doi.org/10.26593/jihi.v13i1.2670.45-60.

Sabirin, Tabrani, ed. Menggugat Terorisme. Jakarta: Karsa Rezeki, 2002.

Sasongko, Joko Panji. “ISIS dan Fenomena Radikalisme Keagamaan Kelas Menengah.” cnnindonesia.com, 1 Februari 2017. https://www.cnnindonesia.com/ nasional/20170201135943-20-190578/isis-dan-fenomena-radikalismekeagamaan-kelas-menengah.

Suprapto, Suprapto. "Aksi Terorisme: Dari Gerakan Ideologis ke Gerakan Inkostitusional." Jurnal Sosiologi USK 12, no. 2 (2018): 143-60. http://jurnal.unsyiah.ac.id/JSU/article/view/12598.

Tim Liputan Tempo. "Investigasi: Paham Radikal di Kampus Kita." Majalah Tempo, 27 Mei 2018.

_—_. "Timang-timang Boom." Majalah Tempo. 21-27 Mei 2018.

Yahya, Harun. Teroris Hanya Takluk oleh Cinta. Jakarta: Iqra Insan Press, 2004. 
This page intentionally left blank 